\title{
Flow And Strength Characteristics Of Clsm Using Brick Powder As Fine Aggregates
}

\author{
Ravindra P.K., Dr.Vaishali G.Ghorpade, Dr.Udayashankar \\ 1) Associate Prof. Govt. Engineering College, Ramanagara 562159 Karnataka, India \\ 2) Associate Prof. \& HOD Civil Engg. Dept. J.N.T.U College of Engineering, Ananthapur-515002, Andhra \\ Pradesh, India \\ 3) B.C. Prof. \& Head of Dept. Civil Engineer, RVCE Bangalore, Karnataka, India
}

\begin{abstract}
Strength is not the only property for which cement based composites are processed. There are many practical situations where enhanced workability is required for placement with the requirements of strength being far lower than normal for which cement mortars and concretes are processed. These are Controlled Low Strength Materials (CLSM) with required flow characteristics such as self-leveling ability, free from settlement after hardening with potential to develop low strength in the range of 1 to $10 \mathrm{MPa}$. Presently the use of CLSM in practice is ahead of development of appropriate technology to handle a very wide spectrum of practical needs of flow characteristics and to handle combinations with a wide spectrum of materials. In this investigation it is attempted to develop a phenomenologieal model within the basic framework of Lyse Rule, already explored in concrete technology. The basic tenet of this law is that the basic property of present mix is in a particulate state similar to saturated clays. In this fresh state, shearing resistance of the mix is a function of total water content similar to saturated clays. Spread flow test and strength test on mixes with low cement content and high volume fly ash and GGBFS combinations with Brick powder as fine aggregate as well as with only cement and fly ash pastes are conducted. Thus generated data is analyzed to advance a phenomenological model. The validity or this model is verified with an independent set of data generated for this purpose.
\end{abstract}

Keywords: - Controlled Low Strength Materials (CLSM): Lyse Rule: Spread Flow Test Phenomenological Model. Abrams Rule: Compression strength test phenomenological model.

\section{INTRODUCTION}

Apart from strength levels to be realized for conventional usage, there are many practical situations, such as, pavement bases, erosion control blankets, filling of utility trenches, backfilling foundations excavations, underground storage tanks. abandoned sewers and utility lines and underground mine shafts require enhanced workability of mixes used for this purpose. These are usually low cement-based materials with appreciable quantities of byproducts of industries such as fly ash from thermal power plants and slag from ferrous industries and Brick powder from brick industries. For these combinations, obviously, the strength development would be far lower than normal concretes mixtures. These are controlled low strength cement based materials (CLSM) defined by Cement and Concrete Terminology" (ACT 229-1994) [1] as materials that result in a compressive strength of 8.3 MPa or less. Currently CLSM applications require unconfined compressive strengths of $2 \mathrm{MPa}$ or less, so as to allow future excavation of CLSM after hardening. The upper limit of 8.3 MPa allows the use of this material for structural fill under buildings where future excavations are unlikely. These materials are also regarded as flow fills, since they are liquid like materials that would set to the consistency of stiff clay. Some of the specific benefits of controlled low strength materials realized as early as 1993 [2] are that, no compaction with consequent minimum labor costs, accelerated construction due to enhanced flow and self-flowing characteristics. Work can be undertaken under all weather conditions and even under freestanding water. Besides CLSM should not be confused with compacted soil - cement, because CLSM requires no compaction (consolidation) or curing to achieve the desired strength unlike soil cement. These class of materials offer a direct means to utilize wide spectrum of waste materials which otherwise pose a problem in their safe disposal.

CLSM is a combination of sand, fly ash and small percent of cement, water and admixtures. Sand is the major component of most of these flowable fills. Consequently, using a waste material such as rock dust, Cinder, Marble powder, brick powder, bottom or ponded ash as a substitute for natural sand would be in the beneficial use of waste material. Other benefits of processing flowable fills are limited labor component, accelerated construction, ready placement in all inaccessible zones and the ability to manually re-excavate for relaying utilities if required. CLSM mixtures may be used for pavement bases, sub bases and sub grade. A wearing surface is required over CLSM since it has relatively poor wear resistant properties. CLSM can be readily placed into a trench hole or other cavity with out any compaction. While backfilling against retaining walls, wherein the lateral pressures exerted on the wall by flowable CLSM may be of concern, CLSM may be 
placed in layers with each layer allowed to harden prior to placing the next layer. CLSM can be used for foundation support. In the ease of weak soils, it can distribute structural load over a greater area, because of its strength, CLSM may reduce the required thickness or strength requirements of the slab.

\section{RESEARCH SIGNIFICANCE}

Presently the use of CLSM in practice is ahead of development of appropriate technology to handle a very wide spectrum of practical needs of flow characteristics and strength characteristics apart from handling combinations and variations in wide spectrum of materials. A rational, rapid and simple method to arrive at the combination of ingredients to realize a specific value of strength development at required age is desirable due to the following situations that might arise in handling large volumes of CLSM.

(1) The strength requirements and the age at which the specific strength is needed vary dependent on the end use. The flow characteristics also vary over a wide range depending upon the practical situation. As such to optimize the use of materials, particularly to minimize the use of cement, simple processing methods are needed.

(2) As the number of ingredients to be combined increases, it is rather difficult to arrive at the needed combination only by resorting to number of trials.

(3) The batches of these materials may themselves vary from time to time which needs required quality control to recheck the mix proportions with minimum test data and computations.

In a wider context, if the method advanced underscores a basic framework, it lends additional support and confidence to employ the same in practice.

\section{SCOPE OF RESEARCH}

It is obvious that to realize the contemplated strength, concrete under normal circumstances has to be placed in a dense homogeneous state without any segregation or bleeding, apart from creating conducive environment for hydration. This is reflected by the workability of concrete mixes. The two basic principles extensively examined are Abrams Law (1918) to take care of the strength development with age and Lyse Rule (1932) to control the workability for proper placement of concrete with adequate workability with potential for strength development. The Lyse Rule states that:

For given materials the CONSISTENCY OF FRESH CEMENT CONCRETE is determined exclusively by the free water content of the mix. This is LYSE'S rule (1932), i.e., constant water content for constant concrete consistency. Thus for a given material, a particular consistency of the fresh concrete is independent of the water-cement ratio of the mix.

According to Lyse rule it is not possible to assess the flow characteristics as water content changes for all combinations of ingredients, since specific water content can cause a particular level of consistency for a given set of ingredients. As any one ingredient in the set changes the amount of cementing paste and proportions of coarse constituents also change. Hence even for the same level of water content altogether different level of consistency is possible. Further the normal classification of workability is presently over a range, which is too wide for classifying the workability to a specific type. viz., very low, low, medium high and very high. Owing to this, trial mix is arrived at based on empirical considerations and tested for its workability. If the workability obtained for this trial mix does not meet the practical requirements, adjustments to water content are made until it is possible to arrive at water content to be adopted to arrive at final mixture proportions to meet the workability envisaged in practice holding water- cement ratio constant from strength point of view. It is evident that for various combinations of cementing materials along with different type of fine aggregates, it is not possible to arrive at functional relations only from theoretical considerations. The possibility of developing a Phenonienological Model to take care of this situation merits examination. A phenomenological approach is one by which, the combination of parameters would be done within the basic framework of a law. The use of this model needs an input of experimental data of a single trial to account for the synergy between different constituents of a given set of materials. If any one ingredient in their combination is changed, the ingredients of the set change. For this new set, the new in put data is to be generated again to use the same phenomenological model to obtain the corresponding water content to arrive at the appropriate mix proportions to meet the specific workability requirements. This exercise is identified as 'Re-proportioning Method'. This is akin to making adjustments to the trial mix until the specified requirements are met with. Instead of repeated laboratory trials, introducing the experimentally determined reference value of workability for a specific water content and make simple calculations to obtain combinations that would satisfy the practical requirements. This is a rapid exercise and has further potential to determine the water content values that would enable to obtain whole spectrum of 
mixes that would have a wide range of workability with the potential to develop strength over a desired range since water- cementing material ratios are maintained constant in each of the cases.

\section{BASIC PRINCIPLES CONTROLLING FLOW OF FRESH CLSM MIXES}

Fresh CLSM mixes can be regarded as a concentrated dispersion of solid particles in a fluid phase, exhibiting the characteristics of a particulate soil material. The cementing material paste coats fine aggregate particles playing the dual role of separating the fine aggregate particles from direct contact preventing frictional interference with each other. Simultaneously paste holds coarse constituents in a dispersed state through the cohesive membrane. As such the cementing material paste plays a dominant role of imparting needed cohesive characteristics to the entire CLSM mix. It has been possible from soil-concrete analogy (Nagaraj. et.al., 1989) to propose the basic framework for development of phenomenological model could be identified.

\subsection{Macro- parameters}

In a parallel situation, it has been shown in the case of saturated clays (Nagaraj and Jayadeva, 1981) that water content at liquid limit represents the water holding capacity of soils reflecting the clay - water physico-chem ical interactions with identical shear strength. The variation of shearing resistance as water content changes in relation to liquid limit water content controls the flow behavior. It has been amply discussed elsewhere (Nagaraj. et.al. 1994: Nagaraj and Miura 2001) as to how water content at liquid limit can be regarded as a possible reference state for analysis and assessment of soil behavior. For each of the clay the penetration depth of the cone of liquid limit apparatus increases as water content increases tracing a flow path. Upon normalization by the corresponding water content at liquid limit state corresponding to $20 \mathrm{~mm}$ penetration all flow lines collapse to a narrow band. For all clays the path of w/wL versus penetration falls in a unique band.

In order to examine the applicability of same considerations when cement as interacting material a set of data generated for this purpose has been analyzed in the same way [5]. It can be seen in figure 1 that data of three clays along with the flow paths of cement paste, 1:1 and 1:2 cement mortars can also be normalized by water content at $20 \mathrm{~mm}$ penetration obtained in a fall cone liquid limit test. Again a narrow band within which all the normalized data falls can be noticed. This suggests that the shearing resistance at different penetration as water contents of clays and cement based composites vary influence the flow behavior.

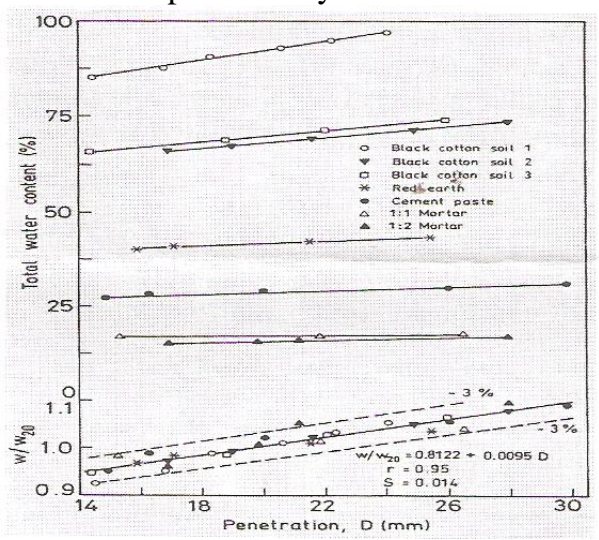

Fig.1 Flow lines of clays and cement based materials \& their Normalization (Nagaraj et al 1989)

It is obvious that all the solid constituents in soils and cement based materials are not made up of only interacting particulate media i.e.. either clay or cement with water. The other constituents such as sand and silt in soils and sand in cement based materials are non-interacting particulate materials with water. In order to examine the role of these coarse inert constituents diagnostic experiments are conducted. Bentonite clay was mixed with different proportions of sand or glass particles and corresponding liquid limit was determined. The flow lines obtained are presented in figure 2 .

The reductions in liquid limits for a given percent of coarse fractions were of the same order despite two fold variations in surface frictional characteristics between sand and glass particles. This suggests that the flow characteristics are controlled primarily by clay, the interacting particulate material. As such it can be premised that coarse inert constituents get a sheath or a cohesive membrane of clay inhibiting direct frictional interference between sand and any other coarser constituents.

The above interdisciplinary examination of interacting particulate material clay and cement suggests that the shearing resistance of the mix is dependent on water content. Further the role of coarse constituents such as sand, silt, non-interacting particulate material is to dilute the potential of interacting particulate material proportionately. The clay or cement paste provides a sheath over coarse material preventing their direct 
contribution to the frictional shearing resistance to the mix of interacting and non interacting particulate material with water.

In a similar way as has been possible to identify liquid limit water content of clay as reference macroparameter, in cement based composites such a parameter has to be arbitrarily chosen. How far flow at particular water content of each of the combinations of cementing materials with fine aggregates can be considered as reference value similar to liquid limit of clays merits examination.

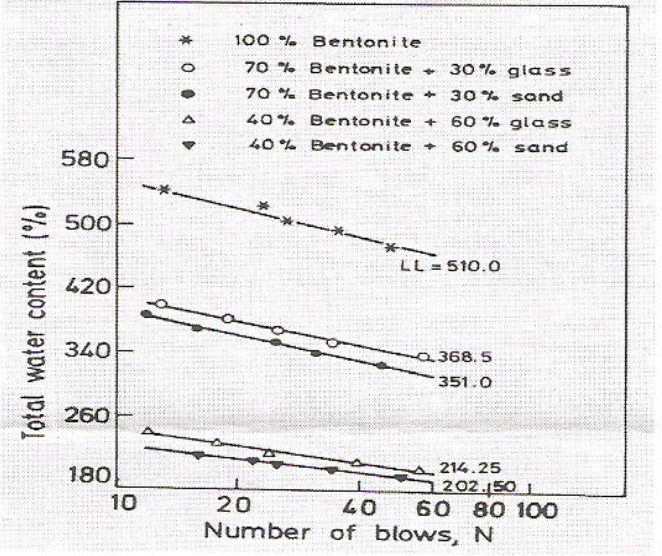

Fig 2 Flow lines for Bentonite and Bentonite sand or glass Particle mixtures

\subsection{Materials and method}

\section{EXPERIMENTAL INVESTIGATIONS}

The Ordinary Portland Cement of 53 grade with a specific gravity of 3.14 and initial and final setting time within prescribed limits as per the IS: 12269 - 1999 [9]. The fly ash used in this investigation has been procured from Electrostatic precipitator of Raichur Thermal Power Station, Raichur, Karnataka State, India. The specific gravity of the fly ash is 2.4. The Lime reactivity as per IS 1727-1967 [10] is 7.47 MPa. Soundness of pozzolana cement mix was obtained from Le-Chatelier apparatus and it is in confonnity with IS 4031-1988 [11]. The results of the soundness test indicate that the expansion was very less and hence it did not disqualify mortars with this ash.

Chemical analysis conducted on the ash indicates that the ash conforms to the requirements of IS: 3812 - 1981 [11]. It is observed that content of $\mathrm{SiO}_{2+} \mathrm{Al}_{2} \mathrm{O}_{3}$ is 88 percent for the ash against minimum of 70 percent stipulated for Pozzolanic material in IS: 3812-1981 [12].

An XRD study confirmed the presence of crystalline phases of Quartz and Mullite in the matrix of alumino silicate glass. SEM study of the ash indicates that almost all the particles are spherical and smooth. Some of them are even smooth spheroids of size $1-5 \mu$ with the majority being less than $3 \mu$ in size. The fine aggregate used is Brick Powder with finer particles $<850$ microns having specific gravity of 1.56 SP-430 is a super-plasticizer, which imparts increased workability without affecting long-term strength and durability. Viscosity modifying agent is used with all mixes to minimize bleeding

\subsection{Tests conducted:}

a. Fresh state - Spread flow table test

b. Hardened state -Strength test on cylindrical specimen of $40 \mathrm{~mm}$.dia $\mathrm{x} 80 \mathrm{~mm}$ height using strain rate controlled compression test:

Variable parameters considered in this investigation:

A. Fly ash-Cement Ratio (F/C) or $(\mathrm{F}+\mathrm{G}) / \mathrm{C}: 6.66,4,3.33$

B. Water-Cementations Ratio w/c+F or $(\mathrm{w} / \mathrm{C}+\mathrm{F}+\mathrm{G}): 0.6,0.7,0.8$

C. Water content (Water/Total solids): 30, 35, 40 percent

D. Strength tests at the age of 7, 28 and 56 days As an example the following table 1 illustrates the different combinations of ingredients.

\subsection{Flowable slurries}

The flow behavior of the mixes is determined by spread flow test [13). The apparatus for this test consists of a mould in the form of a frustum of a cone. $60 \mathrm{~mm}$ high with $70 \mathrm{~mm}$ top diameter and $100 \mathrm{~mm}$ at the base. Since the mixes does not contain coarse aggregate this test is in order to assess workability. The cone placed on a base plate of about a meter in dianieter is filled with the mix of combinations of solid constituents at different water contents is tilled without any air entrapment and slowly lifted. Due to its own weight the mix 
spreads whose diameter in mutually perpendicular directions is measured and averaged. The relative flow area, RFA is calculated from the relation:

$\operatorname{RFA}=\left(\mathrm{D}^{2}-100^{2}\right) / 100^{2}=\{\mathrm{D} / 100\}^{2}-1$

Where $\mathrm{D}$ is the average diameter in $\mathrm{mm}$. It has been observed that the spread increases with water content and the relative flow area is in the range of 5 to 15 which is of self flowing and self leveling consistency as needed for controlled low strength materials. From the mix prepared for measurement of flow behavior cylindrical samples are cast for determination of strength development at different ages. It can be seen in table-2 with cement, fly ash and GGBFS combinations, as an example, the relative flow area increases with increase in water content. This is in accordance with Lyse rule depends on age strength increases accordance Abrams Rule.

Table 1: With 150gms cement as reference, the quantities of other materials GGBFS, Fly ash \& Brick Powder in 1:1 Mortars for above variables

\begin{tabular}{|c|c|c|c|c|c|c|c|c|c|}
\hline \multicolumn{10}{|c|}{ Materials calculations for different combinations@1:1.5 Mortar } \\
\hline $\begin{array}{c}\text { Sl } \\
\text { No }\end{array}$ & Series & $\begin{array}{l}\text { W/B } \\
\text { Ratio }\end{array}$ & $\begin{array}{c}\text { W } \\
\text { in } \%\end{array}$ & $\begin{array}{l}\text { B/W } \\
\text { Ratio }\end{array}$ & $\begin{array}{l}\text { Cement } \\
\text { in gms }\end{array}$ & $\begin{array}{l}\text { Fly ash } \\
\text { in gms }\end{array}$ & $\begin{array}{l}\text { GGBFS } \\
\text { in grms }\end{array}$ & $\begin{array}{l}\text { QD in } \\
\text { gms }\end{array}$ & $\begin{array}{l}\text { Water } \\
\text { in ml }\end{array}$ \\
\hline \multirow[t]{3}{*}{1} & \multirow{3}{*}{$\begin{array}{l}(\mathrm{F}+\mathrm{G}) / \mathrm{C}=6.66 \\
1: 1 \mathrm{MORTAR}\end{array}$} & 0.6 & 30 & 1.7 & 150 & 1000 & 575 & 1725 & 1035 \\
\hline & & 0.7 & 35 & 1.4 & 150 & 1000 & 575 & 1725 & 1208 \\
\hline & & 0.8 & 40 & 1.25 & 150 & 1000 & 575 & 1725 & 1380 \\
\hline & & & & & & & & & \\
\hline \multirow[t]{3}{*}{2} & \multirow{3}{*}{$\begin{array}{l}(\mathrm{F}+\mathrm{G}) / \mathrm{C}=4.00 \\
1: 1 \text { MORTAR }\end{array}$} & 0.6 & 30 & 1.7 & 250 & 1000 & 575 & 1825 & 1095 \\
\hline & & 0.7 & 35 & 1.4 & 250 & 1000 & 575 & 1825 & 1278 \\
\hline & & 0.8 & 40 & 1.25 & 250 & 1000 & 575 & 1825 & 1460 \\
\hline & & & & & & & & & \\
\hline \multirow[t]{3}{*}{3} & \multirow{3}{*}{$\begin{array}{l}(\mathrm{F}+\mathrm{G}) / \mathrm{C}=3.33 \\
1: 1 \mathrm{MORTAR}\end{array}$} & 0.6 & 30 & 1.7 & 300 & 1000 & 575 & 1875 & 1125 \\
\hline & & 0.7 & 35 & 1.4 & 300 & 1000 & 575 & 1875 & 1313 \\
\hline & & 0.8 & 40 & 1.25 & 300 & 1000 & 575 & 1875 & 1500 \\
\hline
\end{tabular}

\section{TEST RESULTS AND THEIR INTERPRETATION}

Table 2: Typical flow and strength results of Cement, GGBFS, Fly ash Mortars.

\begin{tabular}{|c|c|c|c|c|c|c|c|c|c|}
\hline \multicolumn{10}{|c|}{$\begin{array}{c}\text { Average flow results and average strength development @ 7,28 and } 56 \text { days for different series @ different } \\
\text { combinations }\end{array}$} \\
\hline \multirow{3}{*}{$\begin{array}{l}\text { Sl } \\
\text { No }\end{array}$} & \multirow[t]{3}{*}{ Series } & \multirow{3}{*}{$\begin{array}{l}\text { W/B } \\
\text { Ratio }\end{array}$} & \multirow{3}{*}{$\begin{array}{l}\text { W in } \\
\%\end{array}$} & \multirow{3}{*}{$\begin{array}{l}\text { B/W } \\
\text { Ratio }\end{array}$} & \multicolumn{4}{|c|}{ Experimental Values } & \multirow[t]{3}{*}{ Remarks } \\
\hline & & & & & Flow & & ngth in . & & \\
\hline & & & & & RFA & 7 day & 28 day & 56 day & \\
\hline \multirow[t]{3}{*}{4} & \multirow[t]{3}{*}{$\begin{array}{l}(\mathrm{F}+\mathrm{G}) / \mathrm{C}=6.66 \\
1: 1 \mathrm{MORTAR}\end{array}$} & 0.6 & 30 & 1.7 & 5.42 & 0.207 & 0.352 & 0.412 & $\begin{array}{l}\text { No segregation and } \\
\text { Bleeding }\end{array}$ \\
\hline & & 0.7 & 35 & 1.4 & 6.65 & 0.186 & 0.274 & 0.318 & Bleeding \\
\hline & & 0.8 & 40 & 1.25 & 12.32 & 0.145 & 0.197 & 0.213 & Bleeding \\
\hline \multirow[t]{3}{*}{5} & $\begin{array}{l}(\mathrm{F}+\mathrm{G}) / \mathrm{C}=4.00 \\
1: 1 \text { MORTAR }\end{array}$ & 0.6 & 30 & 1.7 & 4.91 & 0.301 & 0.412 & 0.502 & $\begin{array}{l}\text { No segregation and } \\
\text { Bleeding }\end{array}$ \\
\hline & & 0.7 & 35 & 1.4 & 6.43 & 0.281 & 0.390 & 0.470 & No segregation \\
\hline & & 0.8 & 40 & 1.25 & 11.89 & 0.200 & 0.220 & 0.319 & No segregation \\
\hline \multirow[t]{3}{*}{6} & \multirow[t]{3}{*}{$\begin{array}{l}(\mathrm{F}+\mathrm{G}) / \mathrm{C}=3.33 \\
1: 1 \mathrm{MORTAR}\end{array}$} & 0.6 & 30 & 1.7 & 4.14 & 0.603 & 1.666 & 1.781 & $\begin{array}{l}\text { No segregation and } \\
\text { Bleeding }\end{array}$ \\
\hline & & 0.7 & 35 & 1.4 & 6.10 & 0.500 & 1.271 & 1.932 & Bleeding \\
\hline & & 0.8 & 40 & 1.25 & 11.72 & 0.370 & 0.999 & 1.212 & Bleeding \\
\hline
\end{tabular}

Likewise even the strength decreases with increase in binder/fluid ratios in accordance with Abranis law. Even with age the strength gain also follow the expected pattern. It is interesting to note that when relative flow area as water content varies, all linear paths converge as water content decreases. Similar trend in results were observed even in other eases of cement + fly ash mortars and fly ash, cement pastes.

VII. DEVELOPMENT OF PHENOMENOLOGICAL MODEL

For the analysis and assessment of flow, this investigation concentrates on the possibility of employing Lyse Rule already examined [14] in concrete technology as the basic framework for analysis of slump data. In the present development of phenomenological model, RFA at water content of 35 percent is considered as the reference value. 
By normalization of PTA values in each set of combinations of different ingredients the normalized parameter at each of the water contents tends to be as close as possible (table 2) except for couple of values underlined in the table. Considering the distinctly different combinations examined in this study the variations are well within the experimental variations possible. These ratios, at each of the water contents, for all practical purposes, can be regarded as independent of the different combinations of ingredients. A linear fit of these data points between normalized parameter and water content yield a relation of the form:

$\{$ RFA/RFA $\}=0.055 \mathrm{w}-1.22$

with a correlation coefficient of 0.9813 for sample size $n=27$, where $w$ is water content in percent.

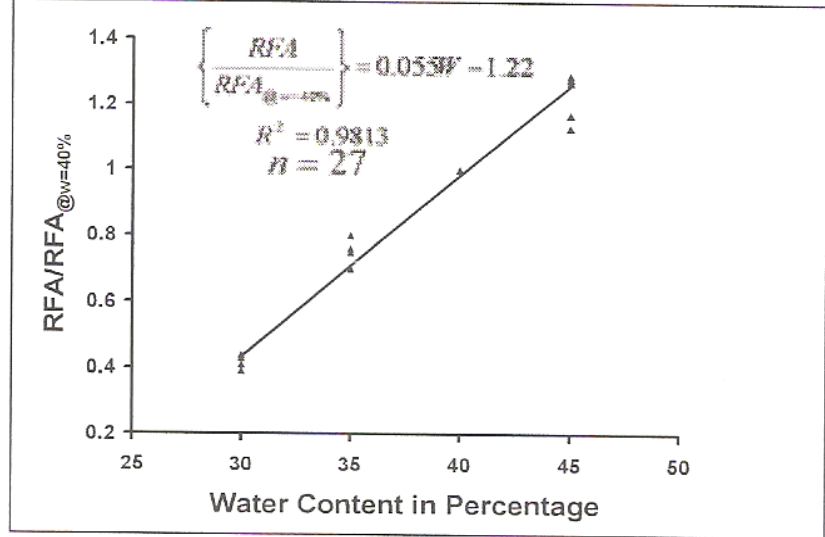

Fig.6. Experimental versus Predicted values for independent set of data

\section{VALIDATION}

An independent set of experimental data (table 2) is generated to examine the level of predictions calculated by the equation 2. For each of the combination of ingredients the predicted values are shown in the column next to its corresponding experimental values.

\section{CONCLUDING REMARKS}

For the combinations of ingredients and the range of water content and binder /fluid ratios the interpretations of experimental data and subsequent analysis permit to make the following concluding remarks

1. The relative flow area (RFA) a reflection of workability follows LYSE RULE which categorically states the flow is a linear function of water content. For every combination there is limiting water content beyond which bleeding takes place. This makes exact assessment of flow and consequently the relation between flow and water content gets distorted.

2. Since the flow paths are not parallel lines there is a possibility of generalization. This fact has been made use of to develop PHENOMENOLOGTCAL MODEL for flow by suitable identification of reference values. By normalization the ratio would be independent of given set of materials.

3. The validation has been examined with respect to independent set of data. The predictions are within the limits of accuracy needed at engineering level. This enhances rapidity in taking engineering decisions with minimum laboratory trials for strength test.

4. As the number of combination of ingredients increase, a rational basis such as developed in this investigation would be very handy to cope with time constraints.

5. With generation of more data and analysis in these lines within a basic framework of LYSE RULE would further reinforce the findings and instill greater confidence in processing of Controlled Low Strength Materials

\section{ACKNOWLEDGEMENTS}

This forms a part of the work carried out Development of Phenomenological Models to Proportion Controlled Low Strength Materials. This experimental study is carried out at RV-Centre for Alternative Construction Materials and Technologies (RV-CALTECH), Department of Civil Engineering. RVCE, Bangalore. INDIA. The authors thank the authorities of RSST, Dr.B.S.Satyanarayana Principal, R.V.C.E Bangalore for the encouragement and Prof Dr.B.C.Udayshankar, Head, Department of Civil Engineering RVCE Bangalore. 


\section{REFERENCES}

[1] ACI Committee 229 (1994) "Controlled Low Strength Materials" (CLSM) (ACI 229R-94) American Concrete Institute. Michigan. 15p.

[2] Janardhanam. R. Burns. F. and Peindl R.D. (1993) "Mix design for flowable Fly ash backfill material." J. Materials in Civil Engineering. ASCE 4(3): 252-263.

[3] Abrams D. 1918. "Design of concrete mixtures". Bulletin No.1 Structural Materials Research Laboratory. Lewis Institute Chicago. p20.

[4] Lyse I (1932) "Test on consistency and strength of concrete having constant water content" Proc. ASTM Vol 32 No.2 pp 629-636

[5] Nagaraj T.S. Sundra Raja Iyengar K.T.and Shashi Prakash S.G. (1989) "Soil Concrete analogy" Principles and potentials Journal of cement and concrete Research, Pergamon press USA 19:534-546

[6] Nagaraj T.S and M.S.Jayadeva 1981 "Reexamination of one point methods of liquid limit determination" Gotechnique 31(3) : 413- 425

[7] Nagaraj T.S. Srinivasa Murthy, B.R. and Vatsala A 1994 "Analysis and Prediction of Soil ABehaviour" Wiley Eastern New Delhi

[8] Nagaraj T.S. and Miura N (2001) Soft Clay Behaviour - "Analysis and Assessment" AA Balkema Rotterdam Netherlands 315P.

[9] IS: 12269-1987 (1999) "Specification for 53 grade ordinary Portland cement.

[10] IS: 1727:1967 (1999) "Methods of test for pozzolanic materials" (first revision)

[11] IS: 4031-1988 (2000) "Determination of soundness test" (first revision)

[12] IS: 3812-1981 (1999) "Specification for fly ash for use of pozzolana and admixture".

[13] Domone P and Chai His Wen (1997) "Testing of binders for high performance concrete" Cement and Concrete Research 27 (8) : 1141-1147

[14] Nagaraj T.S. (1997) "Workability of concrete mixes analysis and assessment" ICI workshop on Recent Trends in Testing of Concrete and Concrete Structures Bangalore. March 1997. 